\title{
Кольцевой волоконный лазер с гибридной гармонической синхронизацией мод и частотой следования импульсов до 12 ГГц
}

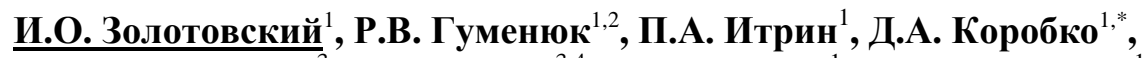 \\ М.А. Одноблюдов ${ }^{3}$, А.Б. Петров ${ }^{3,4}$, В.А. Рибенек ${ }^{1}$ и Д.А. Столяров ${ }^{1}$ \\ ${ }^{l}$ Ульяновский государственный университет \\ ${ }^{2}$ Университет Тампере, Финляндия \\ ${ }^{3}$ Санкт-Петербургский политехнический университет Петра Великого \\ ${ }^{4}$ Национальный исследовательский университет ИТМО \\ *E-mail: korobkotam@rambler.ru
}

DOI: 10.31868/RFL2020.195-196

Солитонные волоконные лазеры с пассивной гармонической синхронизацией мод $(\Gamma \mathrm{CM})$ необходимы в большом числе приложений современной фотоники и обладают рядом принципиальных преимуществ - компактностью, удобным выводом излучения при высоком качестве пучка и сравнительно низкой стоимостью при возможности изготовления из стандартного набора элементов. За реализацию ГСМ в волоконных лазерах могут быть ответственны различные механизмы. Определение механизмов собственно синхронизации мод (нелинейного вращения поляризации, насыщающего поглощения при помощи углеродных нанотрубок, полупроводниковых зеркал и т.д.) и механизмов выстраивания импульсов по гармоникам резонатора позволяет некоторым образом классифицировать ГСМлазеры. Значительный интерес в последнее время вызывают волоконные лазеры на основе т.н. гибридной ГСМ, в которых эффект насыщающего поглощения сопровождается смещением частоты, осуществляемым при помощи оптического модулятора [1]. В этом случае важно заметить, что частота модулятора значительно ниже частоты следования импульсов, т.е. происходит не активная, а именно пассивная синхронизация мод со смещением частоты солитонного импульса. Особенность данной схемы состоит в том, что в определенных случаях смещение частоты вместе со дополнительной спектральной фильтрацией может приводить к стабилизации и повышению качества высокочастотной импульсной последовательности [2]. Основными показателями качества импульсной последовательности являются уровень подавления супермодового шума (SSL) и, в принципе, связанные с ним флуктуации межимпульсного расстояния - временной джиттер. Главной целью данной работы стала разработка солитонного кольцевого ГСМлазера на основе гибридной синхронизацией мод с элементом смещения частоты, способного генерировать мульти-ГГц импульсные последовательности при высоком уровне подавления супермодового шума.

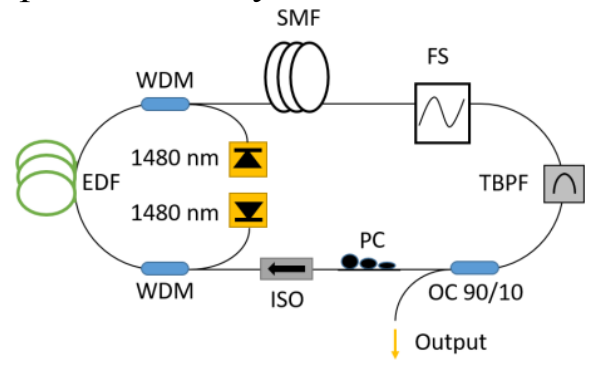

Рис. 1. Схема волоконного лазера с гармонической синхронизацией мод. РС - контроллер поляризации, FS - акустооптический модулятор в режиме сдвига частоты, TBPF - перестраиваемый фильтр, ОС - выходной ответвитель. 
Экспериментальная схема лазера представлена на рис. 1. Результаты эксперимента фиксировались в полосе перестройки фильтра (ТВPF) от 1528 до 1548 нм. Во всей полосе перестройки синхронизация мод на фундаментальной частоте резонатора (3,19 МГц), соответствующая одноимпульсному режиму генерации, происходила при достижении мощности накачки 200 мВт. При увеличении мощности накачки лазер переходит в режим ГСМ. На рис. 2 (a) показаны оптические спектры, соответствующие максимально полученным частотам следования. Отметим, что в коротковолновой (1528-1535 нм) области синхронизация мод характеризуется высокой устойчивостью. Импульсная генерация, полученная в этой полосе при помощи подстройки контроллера поляризации на малой частоте следования, сохраняется при повышении уровня накачки. В этом случае частота следования, импульсов, так же как и выходная мощность, возрастает пропорционально накачке (рис. 2 (b)), при этом важно заметить, что дополнительная подстройка поляризации не производится.
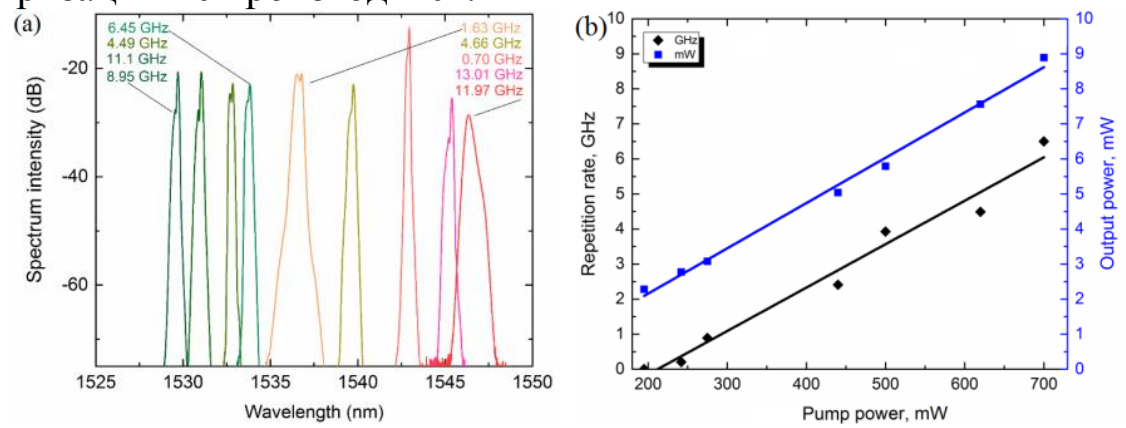

Рис. 2. (а) Оптические спектры, соответствующие указанным максимально полученным частотам следования импульсов. (b) Выходная мощность и частота следования импульсов в зависимости от мощности накачки на центральной длине волны пропускания фильтра $\lambda_{0}=1533.7$ нм.

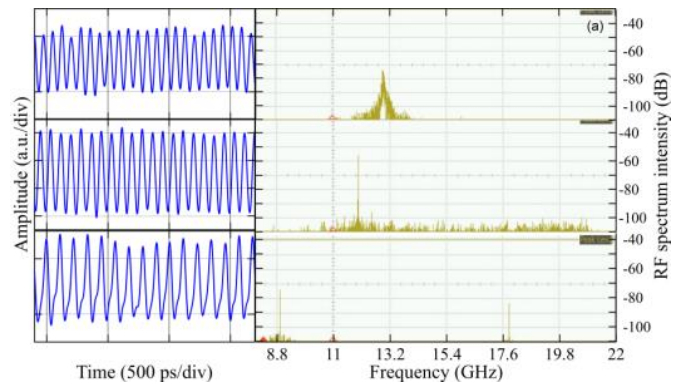

Рис. 3. Осциллограммы и радиочастотные спектры импульсных последовательностей с частотами следования 8.95, 11.97 и 13.01 ГГц на центральной длине волны пропускания фильтра $\lambda_{0}=1529$ нм, 1546.5 нм и 1545.5 нм (снизу вверх) соответственно

В длинноволновой (1535-1548 нм) области перестройки фильтра генерация характеризуются меньшей стабильностью, т.к. эти режимы не являются устойчивыми по отношению к изменению уровня накачки. Тем не менее именно в этом диапазоне перестройки удалось достичь высоких частот следования, превышающих 10 ГГц (рис. 3). На центральной длине волны пропускания фильтра $\lambda_{0}=1546.5$ нм получена импульсная последовательность с частотой следования 11.97 ГГц с высоким уровнем подавления супермодового шума SSL > $40 \mathrm{~dB}$. На $\lambda_{0}=1545.5$ нм получена 13 ГГц последовательность, однако, RF спектр и значительно меньший уровень SSL свидетельствуют о ее слабой устойчивости.

Работа выполнена при поддержке РНФ (проект № 19-72-10037).

\section{Литература}

[1] T. Noronen, O. Okhotnikov, R. Gumenyuk, Optics express 24, 14703-14708 (2016)

[2] R.V. Gumenyuk, D.A. Korobko, I.O. Zolotovskii, Opt Lett, 45, 184-187 (2020) 